\title{
Is there an important moral distinction for medical ethics between lying and other forms of deception?
}

\author{
Raanan Gillon Imperial College Health Service and St Mary's Hospital Medical School, London University
}

In this issue of the journal Ms Jennifer Jackson continues her defence of her thesis that whereas 'we all have a strict duty not to lie, we are not all under a duty of this kind not to deceive intentionally in ways that do not involve lying' (1). In her original paper (2) she argued against the 'common view' that deception that did not involve lying was morally no different from deception that did. If we recognise any duties at all, she claimed, 'we will surely include at least a prima facie duty not to tell lies'. By contrast we do not acknowledge any such prima facie duty against non-lying deception. As evidence of the latter she cited our daily tendency to deceive each other by, for example the wearing of make up, the hiding of baldness, feigned amusement at the feeble witticisms of others and false gratitude for unwelcome presents. The moral duty not to lie was based on the need to maintain trust, she argued, and neither trust nor fellowship within a community are threatened by public toleration of 'the many tricks of deceit we continually practise on one another ...'. Only in cases where the moral obligations of some special relationship exclude it does intentional non-lying deception involve a betrayal of trust and thus become unjust.

Responding to her original paper, Dr David Bakhurst argued (3) that lying and non-lying deception were often morally equivalent and that their wrongness resulted from their infringement of patients' autonomy and or their dignity. Respect for patients' rights and dignity were 'deontological constraints' upon action, to be heeded 'regardless of the consequences'; accounts of moral obligations that were based on the consequences of not accepting such obligations were fundamentally flawed. This applied as much to Ms Jackson's own account of the moral obligation not to lie (because lying damages trust and social cohesion) as to the utilitarian account she criticised (that a moral obligation not to lie maximises welfare). For Dr Bakhurst, doctors' obligations neither to lie nor to deceive patients in other ways, stemmed from the moral obligation not to infringe patients' autonomy and or dignity; exceptions to either might be justified, he implied, in cases that did not threaten such infringement.

Ms Jackson's reply to Dr Bakhurst in this issue points out that she has never argued that lying is always morally worse than non-lying deception; only that 'everyone is under a strict duty not to lie but not under a strict duty to refrain from deception'. Her point seems to be that there are just many more actual and possible instances of morally acceptable non-lying deception than there are of actual or possible morally acceptable lying. Therefore, a general rule against the practice of lying is morally justifiable whereas a general rule against the practice of deception is not.

Such a distinction might be seen as analogous to the moral distinction between killing and letting die; a general moral rule against killing - or at leastagainst the killing of non-aggressors - is accepted while any general moral rule against letting die is eschewed. It is not that all lettings die are regarded as morally acceptable - simply that too many exceptions are morally acceptable for a general moral rule against letting die to be morally justifiable.

However, the important difference between the two cases is that non-killing of non-aggressors is widely regarded as an exceptionless moral obligation, which in the overwhelming majority of countries is exceptionlessly upheld by law. By contrast, it is clear (pace Kant) that non-lying is not and should not be regarded as an absolute and exceptionless moral obligation ('Have you seen the Jew we're after?' ask the SS, when you are sheltering him in your attic: 'You too think I'm fat and ugly, don't you doctor?' demands the tearful, fat and ugly patient). It is morally helpful for doctors to differentiate between killing and letting die, since exceptions to the legal rules against killing non-aggressors must simply be rejected (given that the laws themselves are justified by moral considerations), whereas cases of letting die have to be considered for their moral implications in the particular circumstances before they can be morally decided.

Ms Jackson seems to suggest that a similar distinction applies in cases of lying and non-lying deception; doctors should simply reject lying but they should decide cases of non-lying deception according to their moral implications in the particular circumstances. While no doctor would disagree that cases of non-lying deception should be thus decided, most would reject any exceptionless rule 
against lying, knowing that cases will (rarely) arise in which lying too would be morally justifiable. Indeed Ms Jackson herself seems to equivocate on this issue. On the one hand she writes about a 'strict obligation' not to lie, and about the mind set of honest characters making lying 'just out of the question'; on the other hand she calls the duty not to lie 'prima facie' and writes that provision for exceptions must be made.

Of course if the moral rule against lying were exceptionless - absolute - then her strategy in making a firm moral distinction between lying and non-lying deception would be morally extremely important for without such a distinction any deception, of whatever sort, would be equally and absolutely morally forbidden. But few would claim that the moral obligation not to lie should be regarded as exceptionless. Most would agree that it is morally very important, but most would also agree that it is prima facie - ie it should hold unless some other moral obligation supersedes it. Of course it is always problematical when a very important moral duty is admitted to be overridable; but lies can sometimes be morally justified, as Ms Jackson implicitly admits. While the ugly tearful patient alluded to above affords a relatively minor (though real) example, a more important example was given by a participant at a medical ethics course some years ago.

In years past there was no satisfactory medical treatment for thyrotoxicosis and the operation of thyroidectomy was required. A dangerous and often fatal complication of advanced thyrotoxicosis was so called 'thyroid crisis' or 'thyroid storm', and this could be precipitated by trauma and also by worry, anxiety and anger - including the anxiety of contemplating the prospect of a thyroid operation and its potential risks. Strategies were therefore developed to minimise the risk of thyroid crisis developing in patients who presented with advanced hyperthyroidism and who were at particular risk of thyroid crisis. These strategies involved sedating them, deceiving them, and if necessary lying to them, prior to operating on them as emergencies, not only without their consent, but after major efforts to ensure that they did not realise that they were to be operated on at all. All this was done to prevent an often fatal thyroid crisis - but at the time it was done the patient, ill but not yet in thyroid crisis, was as we would put it these days, 'competent'. It is not necessary to pursue the details of this now obsolete medical problem to realise that given the appropriate 'stage setting', (for example, there would have to be no reason to believe that the patient rejected surgical intervention, even at the cost of his life) deception of a patient, with or without direct lies, might in such rare circumstances be morally justified.

All in all it seems clear that doctors should accept that lying is prima facie wrong but that nonetheless in particular circumstances, both within medical practice and outside it, lying may - rarely - be morally justified. It also seems clear that in medical practice, with its strong commitments and its encouragement and expectations of mutual trust between patient and doctor, non-lying deception would also be morally unacceptable unless there was strong moral justification for it in the particular circumstances; ie in medical practice non-lying deception is also prima facie wrong, even though it may be morally justified in particular circumstances. Thus the apparently inevitable conclusion is that doctors 8 and other health care workers should acknowledge prima facie moral obligations neither to lie to their patients nor to deceive them in ways that do not involve lying: while also acknowledging that in particular circumstances countervailing moral considerations may permit or even require these prima facie moral obligations to be overridden.

\section{References}

(1) Jackson J. On the morality of deception - does method matter? A reply to David Bakhurst. Fournal of medical ethics 1993; 19: 183-187.

(2) Jackson J. Telling the truth. Fournal of medical ethics 1991; 17: 5-9.

(3) Bakhurst D. On lying and deceiving. Fournal of medical ethics 1992; 18: 63-66. 